\title{
Mapping monthly precipitation, temperature, and solar radiation for Ireland with polynomial regression and a digital elevation model
}

\author{
Christine L. Goodale*, J ohn D. A ber, Scott V. Ollinger \\ Complex Systems Research Center, Institute for the Study of Earth, O ceans, and Space, University of $\mathrm{N}$ ew Hampshire, \\ Durham, New Hampshire 03824, USA
}

\begin{abstract}
A $1 \mathrm{~km}^{2}$ resolution digital elevation model (DEM) of Ireland was constructed and used as the basis for generating digital maps of the climate parameters required to run a model of ecosystem carbon and water cycling. The DEM had mean absolute errors of $30 \mathrm{~m}$ or less for most of Ireland. The ecosystem model requires inputs of monthly precipitation, monthly averaged maximum and minimum daily temperature, and monthly averaged daily solar radiation. Long-term (1951 to 1980) averaged monthly data were obtained from sites measuring precipitation (618 sites), temperature (62 sites), and the number of hours of bright sunshine per day ('sunshine hours') (61 sites). Polynomial regression was used to derive a simple model for each monthly climate variable to relate climate to position and elevation on the DEM. Accuracy assessments with subsets of each climate data set determined that polynomial regression can predict average monthly climate in Ireland with mean absolute errors of 5 to $15 \mathrm{~mm}$ for monthly precipitation, 0.2 to $0.5^{\circ} \mathrm{C}$ for monthly averaged maximum and minimum temperature, and 6 to 15 min for monthly averaged sunshine hours. The polynomial regression estimates of climate were compared with estimates from a modified inverse-distance-squared interpolation. Prediction accuracy did not differ between the 2 methods, but the polynomial regression models demanded less time to generate and less computer storage space, greatly decreasing the time required for regional modeling runs.
\end{abstract}

KEY WORDS: Interpolation · Climate grids · DEM · GIS · Regional modeling

\section{INTRODUCTION}

Over the past $50 \mathrm{yr}$, afforestation efforts in Ireland have reversed centuries of forest depletion. A physiologically based model of stand-level photosynthesis and evapotranspiration (PnET; Aber \& Federer 1992, Aber et al. 1995) has been applied to Ireland in order to make regional predictions of forest growth, and to predict the effects of potential changes in temperature, water availability, and nutrient status (Goodale et al. 1998). The model calculates monthly fluxes of carbon and water as a function of 4 climate variables: monthly precipitation, monthly averaged maximum and minimum daily temperature, and monthly averaged solar

*E-mail: christy.goodale@unh.edu radiation. Like other ecosystem models (e.g. Running \& Coughlan 1988, Burke et al. 1990, Raich et al. 1991), PnET can make regional predictions when climate data planes exist for the area of interest (Aber et al. 1993, 1995).

Climate data exist as measurements at discrete points, and many different methods have evolved to generate regional maps from point data. Point data may be interpolated to a regular grid using a variety of methods for determining weights for measured sites, generally as a function of distance or patterns of spatial variance. Interpolation methods include Thiessen polygons, inverse distance interpolations, optimal interpolations or kriging (Dingman et al. 1988, Bacchi \& Kottegoda 1995), or cokriging (reviewed in Creutin \& Obled 1982, Tabios \& Salas 1985 and Hevesi et al. 1992). Other approaches 
extrapolate climate (Running et al. 1987) or precipitation (Daly et al. 1994) using measured climate data, elevation, and established or derived climate-elevation relationships.

While more complex interpolation methodologies exist, simple regression equations relating climate to grid position and elevation can summarize much of the spatial variation in climate data. This approach has been used successfully in the northeastern United States (Ollinger et al. 1993, 1995). This method precludes the need to store 48 large climate maps, as regional maps may be produced by evaluating the equations at each pixel on a digital elevation model (DEM). The DEM is the only map that requires disk storage.

Polynomial regression can describe low-order trend surfaces to summarize smooth, broad patterns of spatial data variation with regard to a coordinate plane. A horizontal plane is zero-order; a tilted plane is firstorder; a quadratic surface with one inflection point along each axis is second-order; etc. Point data can be fit exactly if enough terms are used, but these complicated models often defy logical explanation or physical meaning (Burrough 1986). Regression can summarize strong regional climate trends that have physical meaning, such as decreasing temperature or solar radiation with latitude. As with all regression models, polynomial regression equations should not be used to estimate climate beyond the area from which they are derived.

Trend surfaces alone can suffice in describing spatial climate trends only in regions with little topographic variation because elevation strongly influences climate. On a global average, temperature decreases $6.5^{\circ} \mathrm{C}$ per $1000 \mathrm{~m}$ increase in altitude (Lutgens \& Tarbuck 1995), although this rate varies with location and season. Precipitation usually increases with elevation (Henry 1919, Varney 1920, Hevesi et al. 1992, Daly et al. 1994), but the rate of increase varies substantially, depending on factors that affect the amount of moisture in the air, such as rain shadows or the distance from large water bodies (Schermerhorn 1967, Dingman 1981, Daly et al. 1994).

We developed regression models for Ireland for average monthly precipitation, maximum and minimum temperature, and solar radiation that relate climate to position and elevation on a DEM. The approach aims to use simple equations to summarize large portions of the spatial variability of the climate data. The following sections describe the procedures used to generate and assess the accuracy of an Irish DEM and polynomial regression models of Irish climate. Climate predictions from the regression approach were compared with those from a modified inverse-distance-squared interpolation.

\section{METHODS}

\subsection{Study area}

Resting off the western edge of Europe, Ireland is surrounded by Gulf Stream currents (Fig. 1). This relatively warm water greatly moderates air temperatures near Ireland's coasts (T. Keane 1986, Rohan 1986). Atlantic fronts cross Ireland from the west and southwest to the northeast, bathing Ireland's west coast with ample rainfall (Rohan 1986).

\subsection{G eographic Information System (G IS) structure}

A $1 \mathrm{~km}^{2}$ raster (grid or pixel-based) GIS was designed to fit the Irish National Grid system, which is a 500 by $500 \mathrm{~km}$ grid containing sub-grids with coordinates of northings $(\mathrm{km})$ and eastings $(\mathrm{km})$. The eastern-most $100 \mathrm{~km}$ of the Irish National Grid cover the Irish Sea and were not included in the GIS.

\subsection{Digital Elevation Model (DEM)}

Model development. The DEM was derived from twenty-five 1:126720 ( $1 / 2$ inch:1 mile) maps published by the Ordnance Survey of Ireland (Permit \#6131). $\mathrm{M}$ ap contour intervals indicate elevation to the nearest 100 feet $(30 \mathrm{~m})$. Approximately 21000 points were sampled at regular $2 \mathrm{~km}$ intervals on the Ordnance Survey maps. The elevation from each point was assigned to its corresponding DEM pixel. In addition, the elevations of Ireland's 624 peaks over 1400 feet (427 $\mathrm{m}$ ) were assigned to their corresponding pixels.

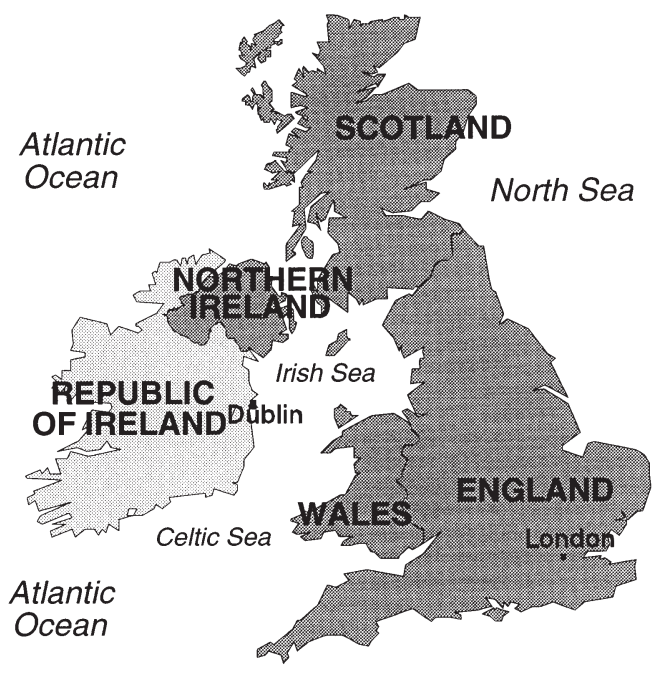

Fig. 1. The Republic of Ireland and the United Kingdom 
For the approximately 63000 remaining pixels, those with filled pixels to the east and west were assigned the average elevation of their neighbors. Blank rows were then filled with the average elevation of the pixels to their immediate north and south. While the averaging procedure smoothed transitions between adjacent pixels, it also produced an inaccurate coastline where 'ocean' pixels (elevation $=0$ ) were averaged with nearby 'land' pixels (elevation $>0$ ), producing 'land' pixels where they should not exist. The DEM 's coast was corrected to fit the coastline of the digitized 1:575000 General Soil Map of Ireland (Gardiner \& Radford 1980).

Eklundh \& M årtensson (1995) reported that DEMs generated from point sampling were as accurate as those obtained from digitized contour lines but required one-tenth of the effort to produce.

Accuracy assessment. Elevations can vary dramatically within $1 \mathrm{~km}^{2}$ (particularly in mountainous regions), and so elevation measured at a point will rarely match the elevation predicted by $1 \mathrm{~km}^{2}$ DEM pixels. The ideal way to assess the accuracy of the DEM is to compare pixel el evations with the integrated elevation of the $1 \mathrm{~km}^{2}$ region that the pixel represents. However, these measurements are rarely made. In place of such data, we compared point measurements of elevation with DEM estimates, with the understanding that the assessment will exaggerate the magnitude of estimated errors, particularly in mountainous regions.

DEM predictions were compared to known elevations for 3 sets of validation points. The precipitation data set (described below), for which elevation and location are published (Fitzgerald 1984), served as one set of validation points. In addition, 2 sets of pixels were chosen at random from the DEM : 98 pixels were selected from any land pixels in the DEM and 96 pixels were selected from areas above $200 \mathrm{~m}$ in order to characterize DEM errors at mid to high elevations. Pixel values were compared with the el evation [estimated to the nearest 100 foot $(30 \mathrm{~m})$ contour interval] at the point on an Ordnance Survey map corresponding to the southwest corner of the pixel.

\subsection{C limate surfaces}

Long-term (1951 to 1980) average monthly climate data were obtained from the Irish Meteorological Service (Fitzgerald 1984, D. Keane 1985, 1986, Rohan 1986) and the Belfast Meteorological Office (1988) (Table 1, Fig. 2).

Precipitation. Data were available for over 800 sites in the Republic of Ireland. Only sites with records spanning at least $28 \mathrm{yr}$ were retained, except for sites above $200 \mathrm{~m}$ for which all records were used. All sites above $200 \mathrm{~m}$ had records of at least $15 \mathrm{yr}$.

Temperature. Over 60 temperature measurement stations recorded daily maximum and minimum temperature values which were averaged by month. Three sites in the center of Dublin were rejected because they showed evidence of urban heat island effects (Landsberg 1981).

Solar radiation. Only 8 sites in Ireland measured incoming solar radiation ( $\mathrm{MJ} \mathrm{\textrm {m } ^ { - 2 }}$ ), and only 1 of these sites existed prior to 1969 (T. Keane 1986). However, several methods exist for calculating solar radiation at any point on a regular grid or digitial elevation model (DEM) based on physical and empirical relationships. Total day length $(\mathrm{N})$ and solar radiation at the top of the Earth's atmosphere $\left(\mathrm{Q}_{\mathrm{a}}\right)$ may be calculated from latitude and day of the year (Swift 1976, Brock 1981, Bonan 1989; based on Milankovitch 1930). Clear-sky radiation may be calculated using empirical (Brock 1981) or mechanistic models (Dubayah et al. 1990) of atmospheric absorbance and scattering. The effects of cloudiness or haziness may be derived from differences between maximum and minimum daily temperature (Bristow \& Campbell 1984), estimates of sky cloud coverage (Bonan 1989), or empirical relation-

Table 1. Characteristics of the measurement sites comprising the precipitation, temperature, and sunshine duration data sets

\begin{tabular}{|c|c|c|c|}
\hline & Precipitation ${ }^{a, e}$ & Max. and min. temp. ${ }^{\text {b,e }}$ & Sunshine hours $\mathrm{s}^{\mathrm{c}, \mathrm{d}, \mathrm{e}}$ \\
\hline No. of sites in data set & 618 & 62 & 61 \\
\hline No. of sites from the Republic of Ireland & 585 & 53 & 49 \\
\hline No. of sites from Northern Ireland & 33 & 9 & 12 \\
\hline M ean duration of records $(y r)^{f}$ & 28 & 26 & 23 \\
\hline M edian elevation (m) & 68 & 52 & 46 \\
\hline Maximum elevation (m) & 806 & 235 & 200 \\
\hline No. of sites with elevation $\geq 200 \mathrm{~m}$ & 84 & 1 & 1 \\
\hline
\end{tabular}


ships with measured hours of bright sunshine per day (sunshine hours) (Brock 1981, Iqbal 1983; based on Angstrom 1924) using the equation:

$$
\mathrm{Q} / \mathrm{Q}_{\mathrm{a}}=\mathrm{a}+\mathrm{b}(\mathrm{n} / \mathrm{N})
$$

where $\mathrm{Q}=$ solar radiation received on the Earth's surface $\left(\mathrm{MJ} \mathrm{\textrm {m } ^ { - 2 }}\right), \mathrm{Q}_{\mathrm{a}}=$ potential solar radiation at the top of the atmosphere (MJ $\left.\mathrm{m}^{-2}\right), \mathrm{n}=$ measured sunshine hours, $\mathrm{N}=$ total day length (h). Values for empirical constants $a$ and $b$ have been defined for Ireland as 0.21 and 0.67 , respectively (M cEntee 1980).

While others have effectively used the difference between maximum and minimum daily temperature to predict daily solar radiation (e.g. Bristow \& Campbell 1984, Running et al. 1987, Glassy \& Running 1994), this method requires calibration for regions with different moisture regimes, and may not be appropriate for extremely wet environments (Bristow \& Campbell 1984). As Ireland's rainfall is high and temperatures are strongly moderated by oceanic currents (an effect of daily temperature ranges that occurs independent of

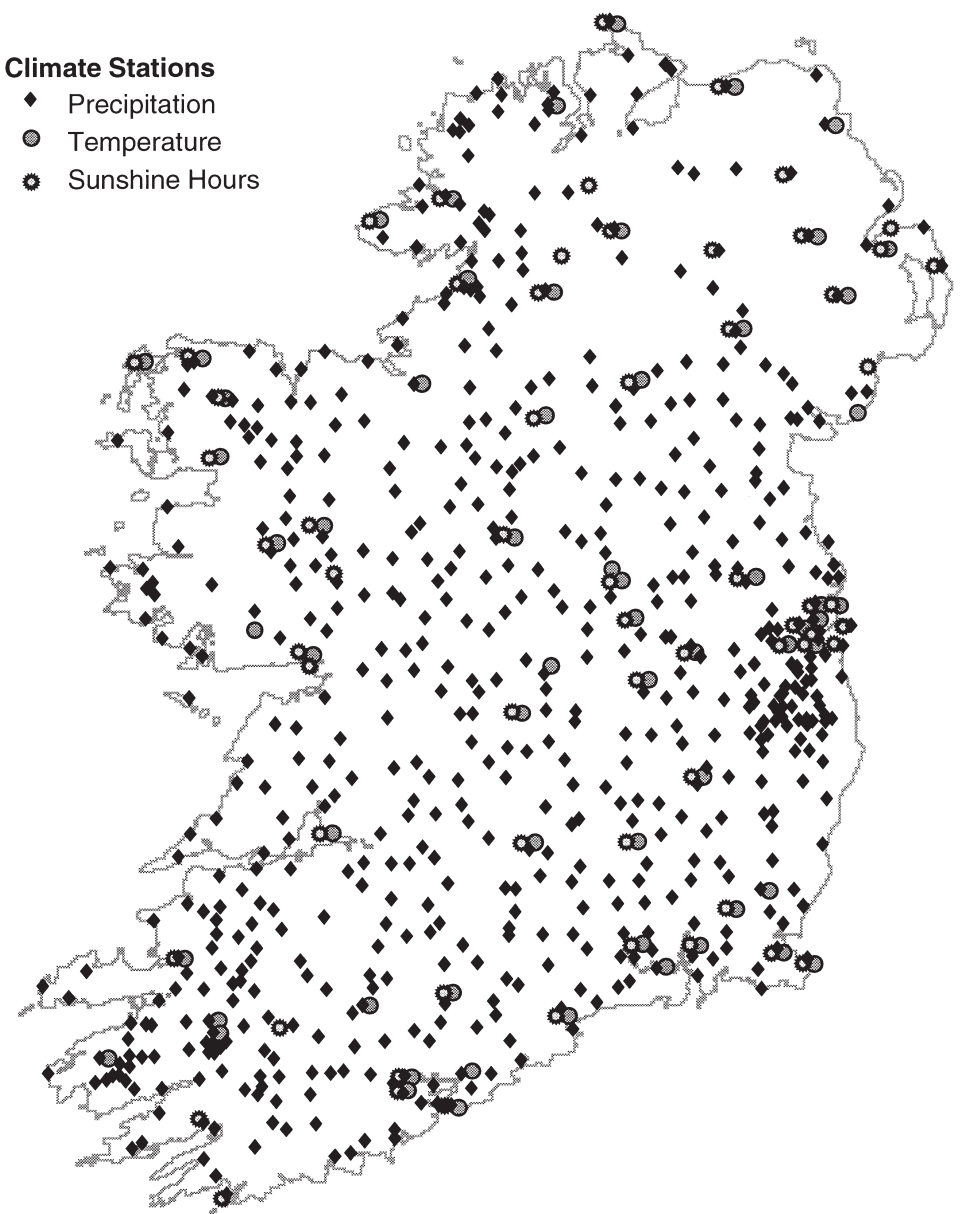

Fig. 2. Location of the precipitation, temperature, and sunshine hour measurement stations in Ireland the degree of cloudiness), we chose not to use the Bristow \& Campbell (1984) approach. Instead, we used the Angstrom-type solar radiation equation (Eq. 1) on account of the ready availability of sunshine hour data.

Over 60 stations have long-term measurements of sunshine hours (D. Keane 1986). One station, Killarney, consistently reported anomalously low measurements of sunshine duration. While the site's measurements may have accurately reflected local trends, the site's inclusion substantially increased errors in preliminary predictions of regional patterns and so it was not included in deriving the regression models.

Model development. Forty-eight climate models (4 climate variables $\times 12 \mathrm{mo}$ ) were derived through polynomial least-squares regression, relating climate to site position and elevation. Each of the 48 climate surfaces took the form:

$$
\begin{aligned}
& \text { Climate value }= \\
& b_{0}+b_{1} \text { row }+b_{2} \text { column }+b_{3} \text { row }^{2}+ \\
& b_{4} \text { column }{ }^{2}+b_{5} \text { row } \times \text { column }+b_{6} \text { elevation }
\end{aligned}
$$

where climate value was precipitation $(\mathrm{mm})$, maximum or minimum daily temperature $\left({ }^{\circ} \mathrm{C}\right)$ or sunshine hours; row $(\mathrm{km})$ was from the top of the 500-row grid; column $(\mathrm{km})$ was from the left of the 400-column grid; elevation was in meters; and $b_{0}$ to $b_{6}$ were coefficients determined with ordinary least-squares regression.

Second-order (quadratic) trend surface models were chosen as the best representation of monthly climate patterns. In aiming for model simplicity, we began with a null model of a zero-order surface, and increased model complexity as long as the models (1) could be justified with physical explanation, and (2) substantially decreased standard errors of prediction. Physically, quadratic models approximate Ireland's shape and generalize the marine effects on Ireland's climate. Preliminary analyses indicated that quadratic models could account for much more variability than linear models could. Higher ordered surfaces explained little additional variability despite their increased complexity. In the few cases where simpler models best fit the existing data, terms ( row $^{2}$, column ${ }^{2}$, or row $\times$ column) were removed from the regressions in order to minimize standard error values.

Terms used to derive a quadratic surface can be inherently collinear (e.g. column, column ${ }^{2}$, and row $\times$ column) (Hamilton 
1992). In some cases, collinearity among regression terms caused the terms' regression coefficients to fail tests of statistical significance. If a model's regression coefficients were not all individually significant at $p<$ 0.05 , then the coefficients of potentially collinear terms were tested jointly with an F-test. The joint F-test determines the probability that all of the examined terms have coefficients of zero (Hamilton 1992). If joint F-tests were not significant at $p<0.05$, then one or more of the collinear terms was removed.

Accuracy assessment. Accuracy was assessed in detail for 8 of the 48 climate models. Two months - the months with the greatest and smallest mean valueswere assessed for each of the 4 climate variables. A portion of each climate variable's data set was randomly selected to serve as validation sites (Table 2). The prediction accuracy of the polynomial regressions was compared with that of a commonly used distanceweighted interpolation.

The existing climate data were divided into 2 separate groups: a base group used to perform estimations, and a test group used to evaluate the predictions (Creutin \& Obled 1982). The test sites were held back, and new polynomial regression equations were calculated from the remaining data. The new equations were used to predict climate at the withheld sites, and predictions were compared with measured values.

The precipitation data set was large enough to withstand removal of at least 100 sites with minimal effects on the recalculated models, but the temperature and sunshine hour data sets were much smaller, allowing removal of only about 15 points. In order to increase the sample size of the accuracy assessments for temperature and sunshine hours, the validation procedure was repeated with a second set of 15 sites that had not been removed the first time. The results present the pooled (30 site) evaluation of the 2 separate accuracy assessments.

A modified inverse-distance-squared interpolation predicted climate for the same validation sites and months was used to assess the polynomial regression procedure. Inverse-distance-squared interpolations calculate values for unmeasured points as the weighted average of values from nearby (in this case, the 6 nearest) measurement stations. Weights are a function of the inverse of the squared distance $\left(1 / d^{2}\right)$ from each station to the unmeasured point. This method cannot explicitly account for the effects of elevation on climate. Because elevation influences precipitation and temperature so strongly, we modified the procedure to account for orographic effects. First, 'sealevel' climate values were calculated for each measurement station for each month of interest according to the station's elevation and the elevation coefficient for the month's corresponding polynomial regression. The 'sea-level' point data (not including the validation sites) were interpolated with the inverse distancesquared procedure to produce a map of 'sea-level' climate. 'At elevation' climate values for each validation site were projected using the predicted 'sea-level' climate value and the station's actual elevation.

Statistics of comparison. The accuracy of the predictions (polynomial regression and the inverse-distancesquared interpolation) were determined by comparing:

(1) The correlation coefficients ( $r$ ) between predicted and observed values.

(2) The biases or sign and magnitude of mean errors:

$$
\text { Bias }=\frac{1}{n} \sum_{i=1}^{n}\left(p_{i}-o_{i}\right)
$$

where $\mathrm{p}_{\mathrm{i}}=$ the predicted value at the point ( $\mathrm{col}_{\mathrm{i}}$, row $\left._{i}\right), o_{i}=$ the observed (measured) value at the point $\left(\mathrm{Col}_{\mathrm{i}}\right.$, row $\left._{\mathrm{i}}\right)$, and $\mathrm{n}=$ the number of points.

(3) The precision or mean absolute errors (MAE) of the 2 interpolation methods:

$$
\operatorname{MAE}=\frac{1}{n} \sum_{i=1}^{n}\left|p_{i}-o_{i}\right|
$$

\section{RESULTS AND DISCUSSION}

\subsection{Digital Elevation Model}

Model development. The final DEM consisted of 116178 one $\mathrm{km}^{2}$ pixels representing ocean and 83822 pixels representing land (Fig. 3). This estimate of land

Table 2. Characteristics of the validation analyses for each monthly climate variable. Accuracy was determined for the 2 months with the most extreme values for each climate variable

\begin{tabular}{|lccrc|}
\hline & Precipitation & Max. temp. & Min. temp. & Sunshine hours \\
\hline No. of sites in total data set & 618 & 62 & 62 & 61 \\
No. of sites with data withheld (validation sites) & 100 & 15 & 15 & 15 \\
No. of sites used to recalculate models & 518 & 47 & 47 & 46 \\
No. of recalculations & 1 & 2 & 2 & May \\
Month with maximum value & Dec & Jul & Jul & Dec \\
Month with minimum value & Jun & & & \\
\end{tabular}




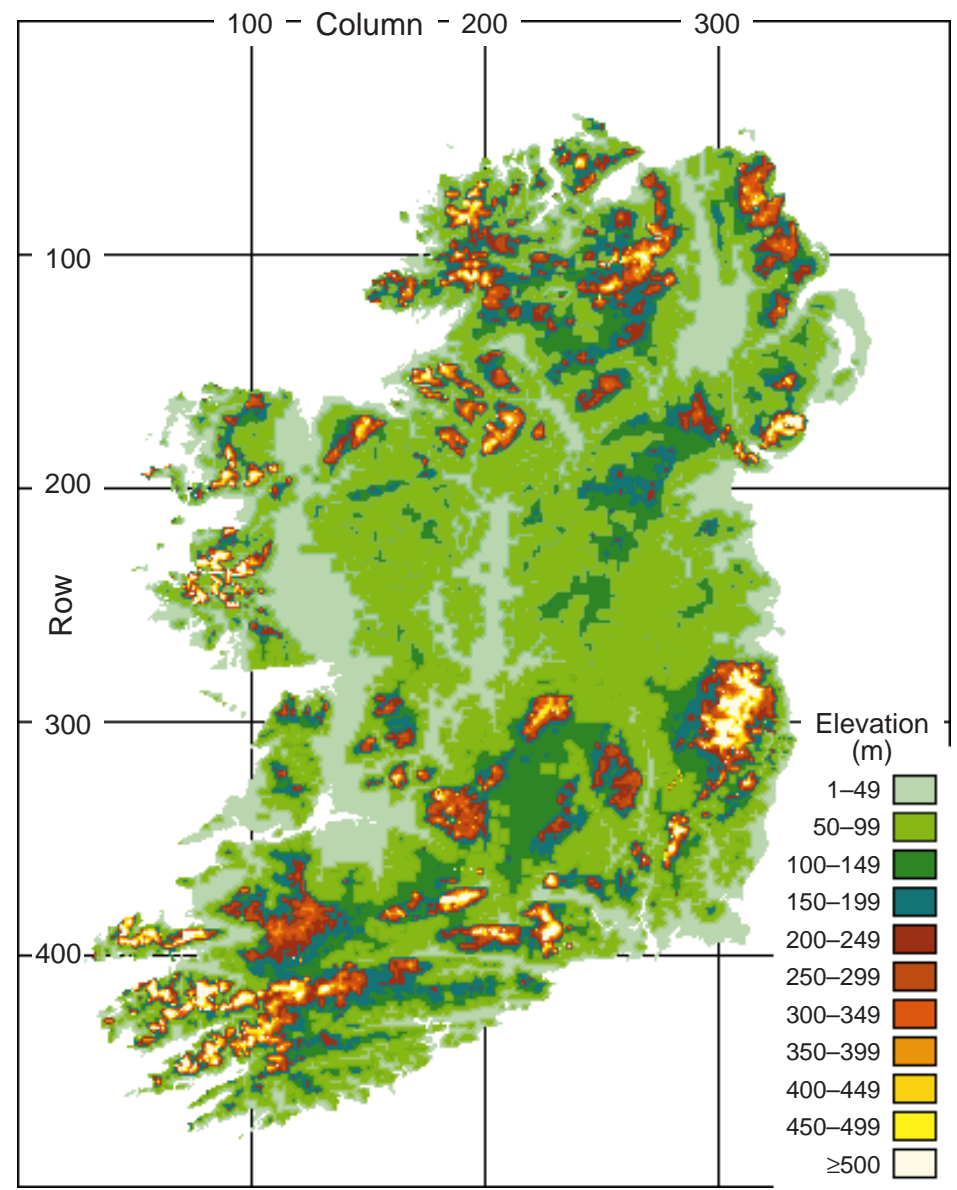

Fig. 3. The digital elevation model (DEM) developed for Ireland. The Irish National Grid, a $500 \times 500 \mathrm{~km}$ planar system of northings and eastings, has been converted to coordinates of $1 \mathrm{~km}$ rows and columns which are shown in the figure

area was within $0.6 \%$ of the combined land, freshwater, and tidal area of the Republic of Ireland and Northern Ireland $\left(84383 \mathrm{~km}^{2}\right.$ ) (Ordnance Survey Office, Dublin). The DEM predicted that $87 \%$ of Ireland's area was below 200 m elevation and that $95 \%$ was below $300 \mathrm{~m}$ (Table 3).
Accuracy assessment. DEM estimates were positively biased compared with all 3 validation sets (Table 4). DEM overestimations were attributed to 2 causes. First, precipitation gages usually exist near population centers, which tend to occur in lowelevation areas. Gage elevations may have been lower than the mean elevation of the surrounding $1 \mathrm{~km}^{2}$. This source of bias would be in the validation data set, not the DEM. The second cause of positive bias in the DEM was that Ireland's 624 highest peaks were included in the DEM as whole $1 \mathrm{~km}^{2}$ pixels when the peaks actually covered a much smaller area. This source of DEM error was most significant in mountainous regions, and can be seen in the larger bias in the above $200 \mathrm{~m}$ validation sites (Table 4). Errors may have been reduced if grid points had been sampled more densely in mountainous regions (Eklundh \& M årtensson 1995).

Approximately $86 \%$ of DEM estimates were within $50 \mathrm{~m}$ of observed values for the precipitation data set and for the 98 randomly selected pixels; $95 \%$ of the DEM estimates were within $100 \mathrm{~m}$ (Fig. 4). For the pixels selected from above $200 \mathrm{~m}$, only $48 \%$ of the point validation values were within $50 \mathrm{~m}$ of DEM values, while $71 \%$ were within $100 \mathrm{~m}$ of DEM values. Mean errors were $90 \mathrm{~m}$ for the above $200 \mathrm{~m}$ set of points. However, due to the considerable variability of point elevations within $1 \mathrm{~km}^{2}$ in mountainous regions, the ability of point values to adequately validate DEM estimates decreases at higher elevations. Pixels above $200 \mathrm{~m}$ comprise only $13 \%$ of the DEM 's total area. Excluding the above $200 \mathrm{~m}$ validation set, the DEM predicted point values with mean errors of $30 \mathrm{~m}$, the same magnitude as the base map contour interval (Table 4).

Table 3. Distribution of elevation for the DEM, and for the observed elevations of 3 sets of validation data: (1) the precipitation data set, (2) a set of points selected randomly from the DEM, and (3) a set of points selected from DEM locations above $200 \mathrm{~m}$

\begin{tabular}{|lcccc|}
\hline $\begin{array}{l}\text { Elevation } \\
(\mathrm{m})\end{array}$ & $\begin{array}{c}\text { Predicted } \\
\text { DEM values }\end{array}$ & $\begin{array}{c}\text { Precipitation } \\
\text { stations }\end{array}$ & $\begin{array}{c}\text { Validation sites (observed values) } \\
\text { Randomly } \\
\text { selected pixels }\end{array}$ & $\begin{array}{c}\text { Pixels selected randomly } \\
\text { from above 200 m }\end{array}$ \\
\hline$<100$ & $57 \%$ & $69 \%$ & $62 \%$ & $3 \%$ \\
$100-200$ & $30 \%$ & $17 \%$ & $28 \%$ & $25 \%$ \\
$200-300$ & $8 \%$ & $6 \%$ & $6 \%$ & $35 \%$ \\
$300-600$ & $5 \%$ & $7 \%$ & $0 \%$ & $2 \%$ \\
$>600$ & $<1 \%$ & $1 \%$ & 98 & 96 \\
Total no. of points & 83822 & 615 & & \\
\hline
\end{tabular}


Table 4. Errors for DEM estimates of 3 sets of validation data calculated as DEM predictions minus observed values (m). Negative errors indicate DEM underestimates, and positive errors indicate DEM overestimates. MAE: mean absolute error

\begin{tabular}{|lccc|}
\hline & $\begin{array}{c}\text { Precipitation } \\
\text { stations }\end{array}$ & $\begin{array}{c}\text { Randomly } \\
\text { selected } \\
\text { pixels }\end{array}$ & $\begin{array}{c}\text { Pixels selected } \\
\text { randomly from } \\
\text { above 200 m }\end{array}$ \\
\hline $\mathrm{n}$ & 615 & 98 & 96 \\
r, DEM vs & 0.89 & 0.83 & 0.46 \\
$\quad$ observed & & & \\
Mean bias (m) & +8.7 & +4.4 & +34.2 \\
MAE (m) & 27.7 & 28.2 & 87.3 \\
\hline
\end{tabular}

\subsection{Climate}

Climate patterns. Mean precipitation, temperature, and sunshine hours (1951 to 1980) varied both spatially and seasonally in Ireland. Rainfall varied dramatically across Ireland with moderate seasonal variation, while temperature and sunshine displayed more seasonal variation than spatial (Fig. 5).

Precipitation: Mean monthly precipitation in Ireland averaged $100 \mathrm{~mm}$ with substantial spatial and seasonal variation. Across Ireland, precipitation varied dramatically from west to east. For sites at sea level, annual precipitation ranged from more than $2000 \mathrm{~mm}$ in the west to less than $800 \mathrm{~mm}$ in the east.

Temperature: Ireland has an oceanic climate of mild winters and cool summers. Average minimum temperatures in the winter were above freezing, and average

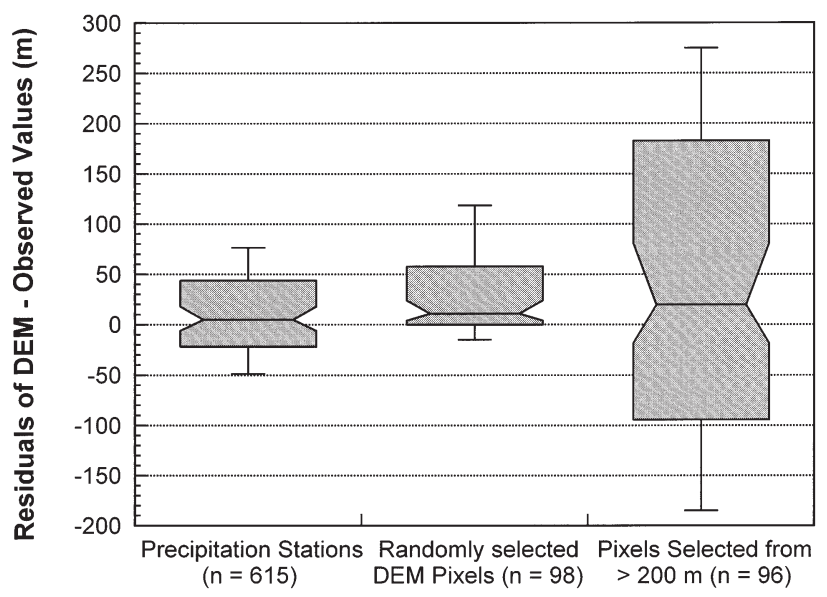

Fig. 4. Box plots of DEM errors. Errors were calculated for 3 sets of validation data as predicted (DEM) minus observed elevation. Horizontal lines indicate the medians, notches the 25th to 75th percentiles, boxes the 10th and 90th percentiles, and whiskers the 5th and 95th percentiles maximum temperatures in the summer were less than $20^{\circ} \mathrm{C}$. Within each month, temperatures varied only 3 to $4^{\circ} \mathrm{C}$ among the 62 measurement sites.

Sunshine hours: M ean sunshine hour measurements related strongly to total day length which varies from $7.25 \mathrm{~h}$ in December to $16.75 \mathrm{~h}$ in J une. Seasonal variability in sunshine hour measurements was far greater than spatial variability among the 61 measurement sites. Spatial variability was greatest during the summer months when sunshine hours varied approximately $2 \mathrm{~h}$ among the sites.

Climate models. Forty-eight regression climate models were derived for Ireland. The models consisted of simple trend surfaces and linear elevation factors (Fig. 6). These simple representations of Ireland's
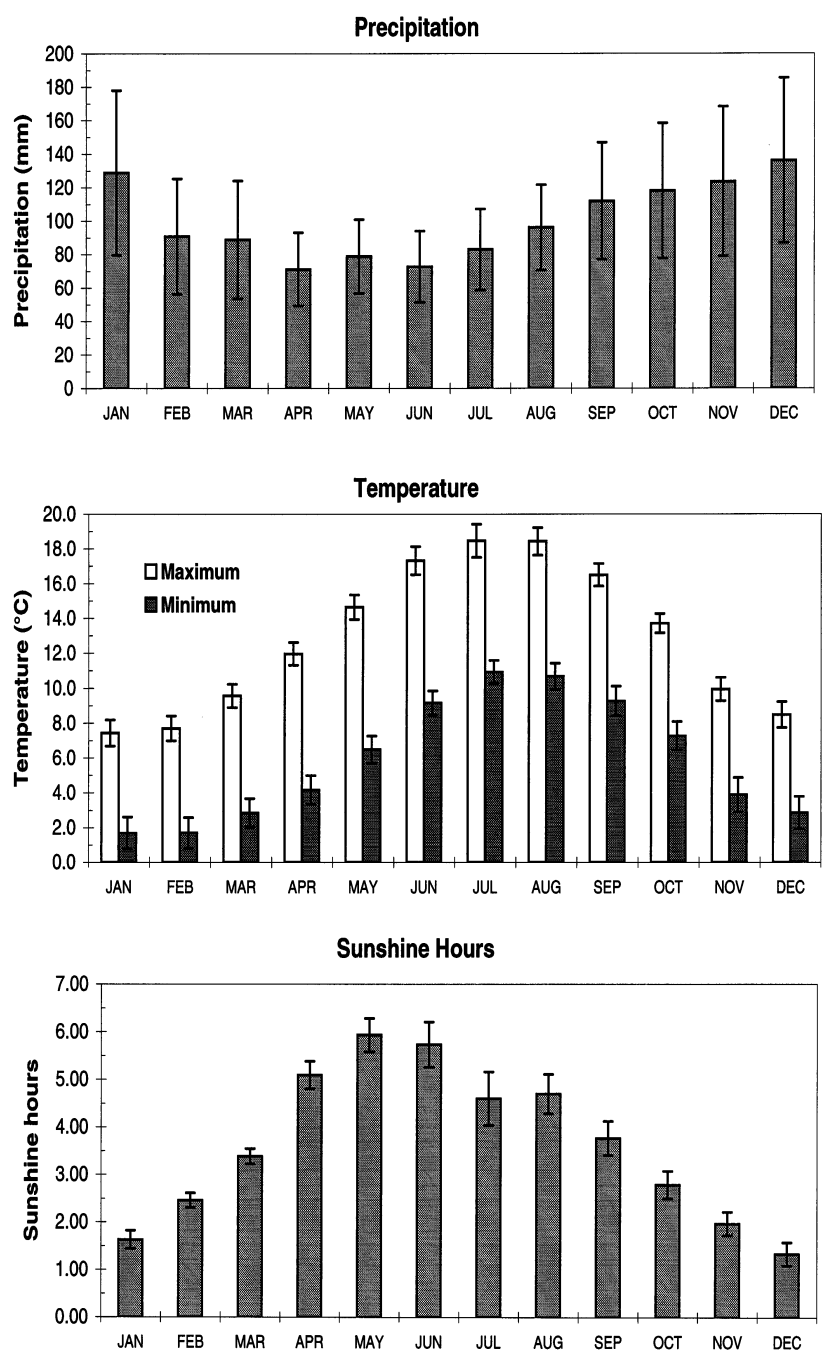

Fig. 5. Mean monthly precipitation, maximum and minimum monthly averaged daily temperature, and monthly averaged daily sunshine hours for Ireland, 1951 to 1980. Bars represent data variability ( \pm 1 standard deviation) among the 618 precipitation, 62 temperature, and 61 sunshine hour measurement sites 


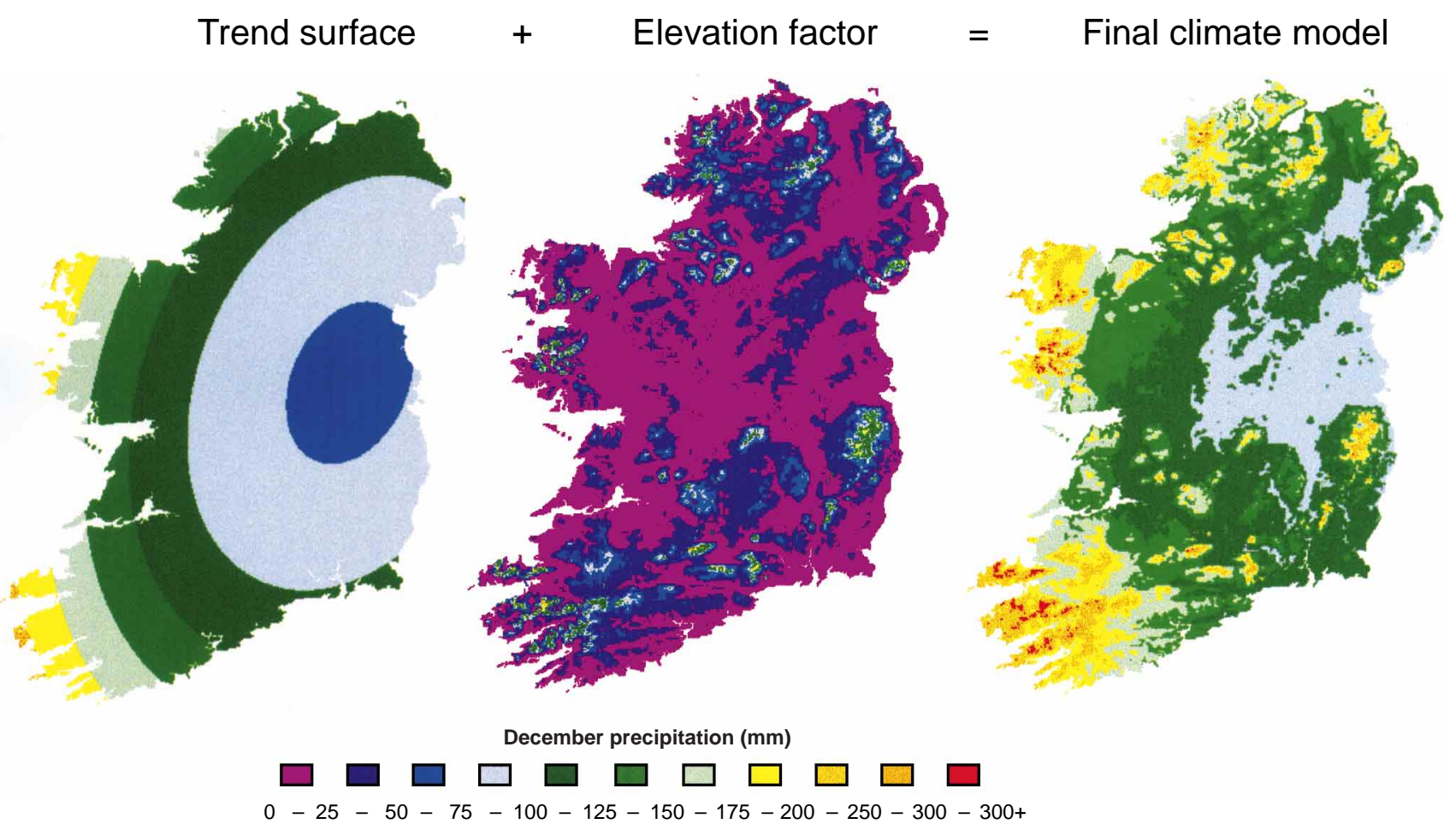

Fig. 6. Regression climate model for Ireland. Trend surface values (left) are combined with linear elevation factors (center) to form a final model for December precipitation (right)

shape and topography accounted for 53 to $93 \%$ of the spatial variability in monthly climate data. The range of climate variability within a month was quite small for the temperature and sunshine hour data sets; yet, simple trend surfaces were still able to describe much of the existing variability.

Precipitation: Polynomial regression equations explained an average of $74 \%$ of the spatial variability of the 618 monthly precipitation records (Table 5). Adjusted $R^{2}$ values varied little throughout the year (Fig. 7). Standard errors of prediction ranged from 11 to $24 \mathrm{~mm}$, roughly corresponding with the magnitude of mean monthly precipitation.

Regression coefficients for elevation $\left(b_{6}\right)$ could be interpreted directly, but the coefficients for row, column, row ${ }^{2}$, and column ${ }^{2}\left(b_{1}\right.$ to $\left.b_{4}\right)$ were difficult to

Table 5. Regression statistics and coefficients for predicting monthly precipitation $(\mathrm{mm})$ from row $(\mathrm{km})$, column $(\mathrm{km})$ and elevation $(\mathrm{m})$. All coefficients are significant at $p<0.001 . \mathrm{n}=618$. Const. $=$ constant, Col. $=$ column, Elev. $=$ elevation, SE $=$ standard error; $\mathrm{Adj} . \mathrm{R}^{2}$ is the coefficient of determination adjusted for the complexity of the model relative to the complexity of the data

\begin{tabular}{|c|c|c|c|c|c|c|c|c|c|c|c|}
\hline & \multirow[b]{2}{*}{$\begin{array}{c}\text { Const. } \\
\mathrm{b}_{0}\end{array}$} & \multirow[b]{2}{*}{$\begin{array}{c}\text { Row } \\
b_{1}\end{array}$} & \multirow[b]{2}{*}{$\begin{array}{c}\text { Col. } \\
\mathrm{b}_{2}\end{array}$} & \multicolumn{4}{|l|}{ Coefficients } & \multirow{2}{*}{ Adj. $R^{2}$} & & \multirow{2}{*}{$\begin{array}{l}\text { Data } \\
\text { mean } \\
(\mathrm{mm})\end{array}$} \\
\hline & & & & $\begin{array}{c}\text { Row }^{2} \\
b_{3}\end{array}$ & $\begin{array}{c}\mathrm{Col}^{2} \\
\mathrm{~b}_{4}\end{array}$ & $\begin{array}{c}\text { Row } \times \text { Col } . \\
b_{5}\end{array}$ & $\begin{array}{c}\text { Elev. } \\
\mathrm{b}_{6}\end{array}$ & & $(\mathrm{~mm})$ & (\% mean) & \\
\hline J an & 396.4 & -1.047 & -1.514 & 0.00162 & 0.00236 & 0.00095 & 0.234 & 0.76 & 23.9 & $19 \%$ & 129 \\
\hline Feb & 270.5 & -0.768 & -1.030 & 0.00125 & 0.00169 & 0.00066 & 0.168 & 0.77 & 16.5 & $18 \%$ & 91 \\
\hline $\mathrm{Mar}$ & 285.0 & -0.770 & -1.136 & 0.00120 & 0.00186 & 0.00069 & 0.163 & 0.74 & 17.9 & $20 \%$ & 89 \\
\hline Apr & 155.4 & -0.325 & -0.495 & 0.00050 & 0.00078 & 0.00023 & 0.122 & 0.72 & 11.6 & $16 \%$ & 71 \\
\hline May & 166.8 & -0.343 & -0.571 & 0.00051 & 0.00091 & 0.00040 & 0.131 & 0.73 & 11.6 & $15 \%$ & 79 \\
\hline Jun & 190.7 & -0.373 & -0.604 & 0.00040 & 0.00090 & 0.00036 & 0.117 & 0.72 & 11.3 & $16 \%$ & 73 \\
\hline Jul & 189.2 & -0.364 & -0.518 & 0.00046 & 0.00074 & 0.00019 & 0.132 & 0.69 & 13.5 & $16 \%$ & 83 \\
\hline Aug & 226.6 & -0.449 & -0.673 & 0.00056 & 0.00097 & 0.00041 & 0.139 & 0.69 & 14.2 & $15 \%$ & 96 \\
\hline Sep & 318.1 & -0.774 & -1.064 & 0.00103 & 0.00146 & 0.00086 & 0.183 & 0.73 & 18.0 & $16 \%$ & 112 \\
\hline Oct & 367.6 & -0.901 & -1.354 & 0.00125 & 0.00203 & 0.00092 & 0.195 & 0.75 & 20.2 & $17 \%$ & 118 \\
\hline Nov & 427.5 & -1.072 & -1.640 & 0.00144 & 0.00248 & 0.00113 & 0.213 & 0.78 & 21.0 & $17 \%$ & 124 \\
\hline $\mathrm{Dec}$ & 411.3 & -1.002 & -1.561 & 0.00145 & 0.00237 & 0.00102 & 0.245 & 0.76 & 24.2 & $18 \%$ & 136 \\
\hline Mean & & & & & & & 0.170 & 0.74 & 17.0 & $17 \%$ & 100 \\
\hline
\end{tabular}



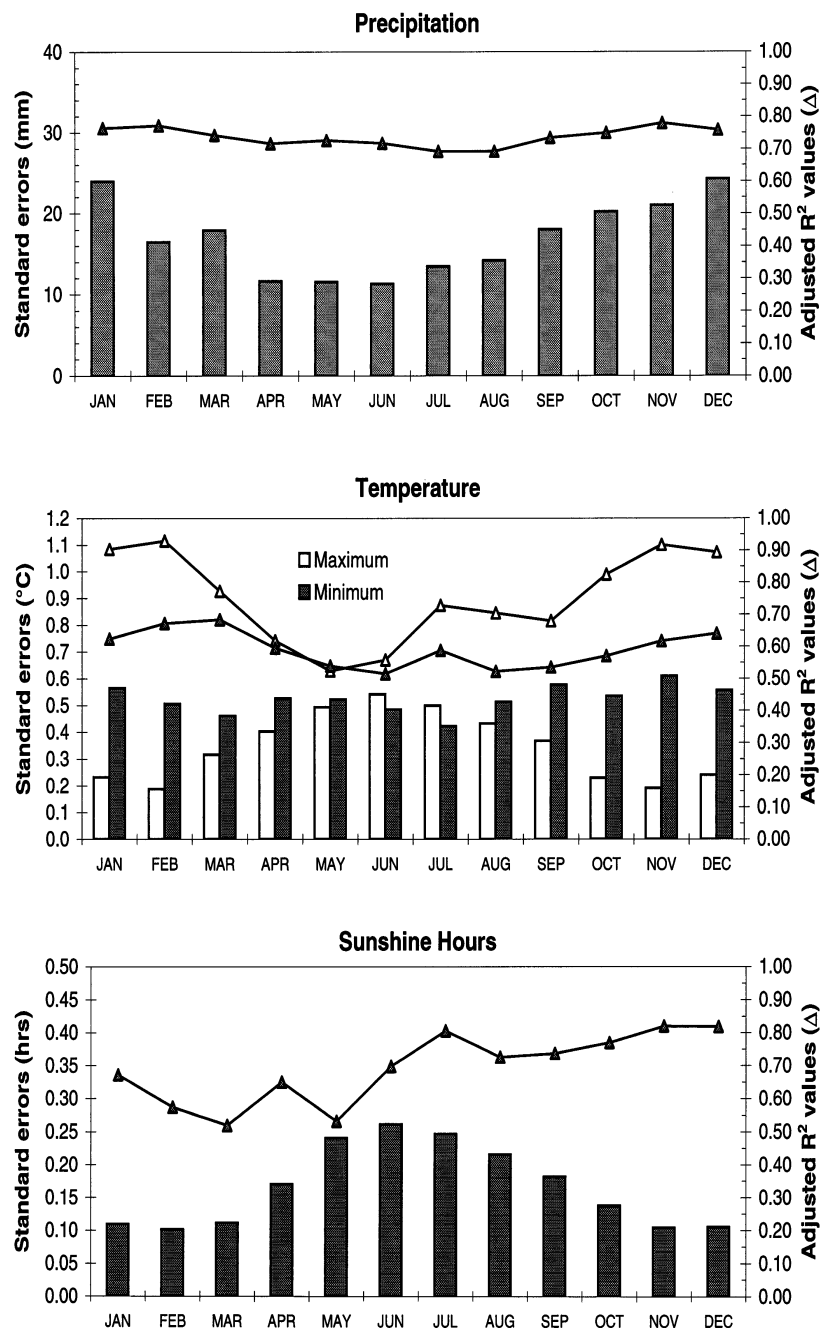

Fig. 7. Seasonal trends in model predictive ability as indicated by standard errors (bars) and by adjusted $\mathrm{R}^{2}$ values (triangles)

interpret quantitatively. However, the signs of these coefficients determined the shape of the climate variable's relationship with respect to the row or column axes. For example, if a month's row coefficient for precipitation was negative $\left(b_{1}<0\right)$ and its row ${ }^{2}$ coefficient was positive $\left(b_{3}>0\right)$, then precipitation decreased from north to south until an inflection point was reached, after which precipitation increased. The same Ushaped relationship occurred along the east-west axis when the coefficient for column was negative and the coefficient for column ${ }^{2}$ was positive $\left(b_{2}<0\right.$ and $\left.b_{4}>0\right)$.

For all months, the coefficients for row, column, row ${ }^{2}$, and column ${ }^{2}$ described $\mathrm{U}$-shaped patterns of precipitation with respect to row and column (Table 5). The east-west inflection point occurred near the eastern edge of Ireland for all months. These coefficients indicated patterns of low rainfall in central-east Ireland with increasing rainfall toward the north, south, and west coasts (Fig. 8).

The positive coefficients for elevation $\left(b_{6}\right.$, Table 5$)$ indicated increasing precipitation with elevation. The rate of increase varied roughly with mean monthly precipitation. Total annual precipitation increased with elevation at a rate of $2040 \mathrm{~mm}$ per $1000 \mathrm{~m}$. For comparison, the annual precipitation/elevation relationship in the western United States ranges from $250 \mathrm{~mm} / 1000 \mathrm{~m}$ in Arizona to $2170 \mathrm{~mm} / 1000 \mathrm{~m}$ in western Washington State (Daly et al. 1994). The latter region experiences climatic conditions quite similar to Ireland's.

Within each month, the elevation coefficient was assumed to remain spatially constant throughout Ireland. However, residual analyses suggested that a spatially constant elevation coefficient underestimated high-elevation rainfall in the west and overestimated it in the east. Two factors could explain this trend. First, greater amounts of total precipitation in the west of Ireland could have caused precipitation to increase more steeply than in the east. Second, the topographic differences between the sharp peaks of the west and the more rounded peaks in the east could have caused different patterns of orographic precipitation (Schermerhorn 1967).

Temperature: On average, polynomial regression equations accounted for $80 \%$ of the spatial variation in monthly averaged maximum daily temperature and $63 \%$ of the spatial variability of minimum daily temperature (Table 6). Standard errors averaged 0.31 and $0.50^{\circ} \mathrm{C}$ for maximum and minimum temperature predictions, respectively. Standard errors for maximum temperature were smallest in the winter $(0.19$ to $\left.0.23^{\circ} \mathrm{C}\right)$ and largest in the summer months $\left(0.47^{\circ} \mathrm{C}\right.$ in $\mathrm{J}$ une). Standard errors for minimum temperature displayed no seasonal trend.

The decrease in maximum temperature per $1000 \mathrm{~m}$ increase in elevation averaged $7.4^{\circ} \mathrm{C}$, while the decrease in minimum temperatures with elevation averaged $8.4^{\circ} \mathrm{C}$ (Table 6). These rates were slightly greater than the normal environmental lapse rate of $6.5^{\circ} \mathrm{C}$ per $1000 \mathrm{~m}$, and were heavily influenced by the single measurement site above $150 \mathrm{~m}$. During the winter, the elevation coefficients for minimum temperature are slightly smaller than those for maximum temperature, possibly as a result of nighttime temperature inversions, caused by cooled air flowing down into valleys. Localized cold-air drainage patterns may be a factor in the poorer fit of the minimum temperature models relative to the maximum temperature models.

The negative coefficients on row and column and the positive coefficients on row $^{2}$ and column ${ }^{2}$ (Table 6) described U-shaped relationships between minimum temperature and both the row and column axes. This 

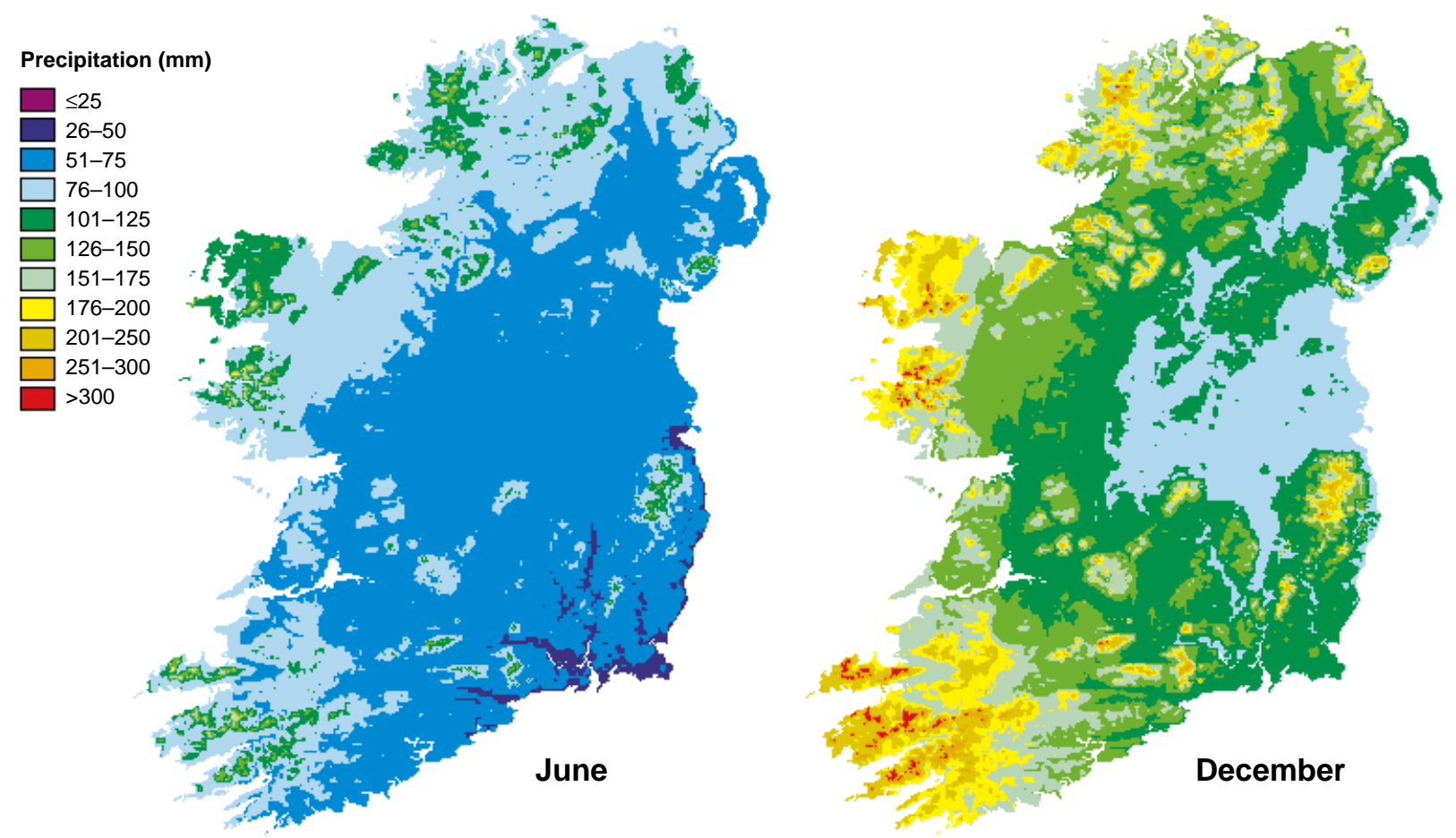

Fig. 8. Average J une and December precipitation $(\mathrm{mm})$ predicted from the coefficients listed in Table 5 and the DEM

Table 6. Regression statistics for predicting monthly averaged maximum and minimum daily temperature $\left({ }^{\circ} \mathrm{C}\right)$ from row $(\mathrm{km})$, column $(\mathrm{km})$ and elevation $(\mathrm{m}) . \mathrm{p}<0.05$ for all coefficients when potentially collinear combinations are tested together. $\mathrm{n}=62$. Abbreviations as in Table 5

\begin{tabular}{|c|c|c|c|c|c|c|c|c|c|c|}
\hline \multirow{2}{*}{ 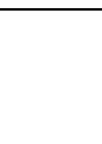 } & \multicolumn{7}{|c|}{ Coefficients } & \multirow{2}{*}{ Adj. $R^{2}$} & \multirow{2}{*}{$\begin{array}{c}\text { SE } \\
\left({ }^{\circ} \mathrm{C}\right)\end{array}$} & \multirow{2}{*}{$\begin{array}{c}\text { Data } \\
\text { mean } \\
\left({ }^{\circ} \mathrm{C}\right)\end{array}$} \\
\hline & $\begin{array}{c}\text { Const. } \\
\mathrm{b}_{0}\end{array}$ & $\begin{array}{c}\text { Row } \\
b_{1}\end{array}$ & $\begin{array}{c}\text { Col. } \\
\mathrm{b}_{2}\end{array}$ & $\begin{array}{c}\text { Row }^{2} \\
b_{3}\end{array}$ & $\begin{array}{c}\mathrm{Col}^{2} \\
\mathrm{~b}_{4}\end{array}$ & $\begin{array}{c}\text { Row } \times \text { Col. } \\
b_{5}\end{array}$ & $\begin{array}{c}\text { Elev. } \\
b_{6}\end{array}$ & & & \\
\hline \multicolumn{11}{|c|}{ Maximum daily temperature } \\
\hline Jan & 9.42 & -0.00375 & -0.01487 & $1.23 E-5$ & $2.63 E-5$ & $5.66 \mathrm{E}-6$ & -0.0086 & 0.90 & 0.23 & 7.4 \\
\hline Feb & 8.24 & 0.00351 & -0.00639 & $-1.18 E-7$ & $7.55 E-6$ & 0 & -0.0084 & 0.93 & 0.19 & 7.7 \\
\hline Mar & 6.88 & 0.01655 & 0.01238 & $-1.84 \mathrm{E}-5$ & $-2.38 E-5$ & $-2.02 E-5$ & -0.0084 & 0.82 & 0.28 & 9.6 \\
\hline Apr & 7.21 & 0.02401 & 0.02405 & $-3.05 E-5$ & $-4.49 E-5$ & $-2.74 \mathrm{E}-5$ & -0.0067 & 0.71 & 0.35 & 12.0 \\
\hline May & 7.91 & 0.02988 & 0.03656 & $-3.97 E-5$ & $-6.74 \mathrm{E}-5$ & $-3.42 \mathrm{E}-5$ & -0.0061 & 0.64 & 0.43 & 14.6 \\
\hline Jun & 9.20 & 0.03391 & 0.04066 & $-4.40 E-5$ & $-6.87 E-5$ & $-3.77 \mathrm{E}-5$ & -0.0054 & 0.66 & 0.47 & 17.3 \\
\hline $\mathrm{Jul}$ & 9.92 & 0.03267 & 0.04082 & $-3.85 E-5$ & $-6.62 E-5$ & $-3.44 \mathrm{E}-5$ & -0.0062 & 0.79 & 0.43 & 18.5 \\
\hline Aug & 11.86 & 0.02637 & 0.03138 & $-3.22 E-5$ & $-5.34 E-5$ & $-2.49 \mathrm{E}-5$ & -0.0061 & 0.75 & 0.39 & 18.4 \\
\hline Sep & 11.95 & 0.02082 & 0.02008 & $-2.49 E-5$ & $-3.18 E-5$ & $-2.11 E-5$ & -0.0072 & 0.73 & 0.34 & 16.5 \\
\hline Oct & 12.86 & 0.00762 & 0 & $-8.16 E-6$ & 0 & $-1.71 E-6$ & -0.0072 & 0.83 & 0.23 & 13.7 \\
\hline Nov & 10.81 & -0.00009 & -0.00779 & $6.80 E-6$ & $1.49 E-5$ & 0 & -0.0091 & 0.92 & 0.19 & 9.9 \\
\hline Dec & 10.87 & -0.00547 & -0.01656 & 1.27E-5 & $2.70 E-5$ & $1.19 E-5$ & -0.0089 & 0.90 & 0.23 & 8.6 \\
\hline Mean & & & & & & & -0.0074 & 0.80 & 0.31 & 12.8 \\
\hline \multicolumn{11}{|c|}{ M inimum daily temperature } \\
\hline Jan & 8.11 & -0.02406 & -0.03968 & $4.02 E-5$ & $7.54 \mathrm{E}-5$ & $3.00 E-5$ & -0.0080 & 0.68 & 0.52 & 1.7 \\
\hline Feb & 7.15 & -0.02098 & -0.03346 & $3.60 \mathrm{E}-5$ & $6.20 \mathrm{E}-5$ & $2.82 E-5$ & -0.0085 & 0.73 & 0.46 & 1.7 \\
\hline $\mathrm{Mar}$ & 7.56 & -0.01690 & -0.02860 & $2.96 \mathrm{E}-5$ & $5.20 \mathrm{E}-5$ & $2.19 \mathrm{E}-5$ & -0.0084 & 0.72 & 0.43 & 2.8 \\
\hline Apr & 9.13 & -0.01684 & -0.03063 & $2.83 E-5$ & $5.62 E-5$ & $2.29 E-5$ & -0.0082 & 0.63 & 0.50 & 4.2 \\
\hline May & 10.59 & -0.01528 & -0.02328 & $2.59 E-5$ & $4.32 \mathrm{E}-5$ & $1.87 \mathrm{E}-5$ & -0.0088 & 0.57 & 0.51 & 6.5 \\
\hline Jun & 12.11 & -0.00976 & -0.01897 & $1.76 \mathrm{E}-5$ & $3.78 \mathrm{E}-5$ & $1.30 \mathrm{E}-5$ & -0.0082 & 0.53 & 0.47 & 9.1 \\
\hline Jul & 12.36 & -0.00365 & -0.00959 & $1.11 E-5$ & $2.28 \mathrm{E}-5$ & 0 & -0.0093 & 0.59 & 0.42 & 10.9 \\
\hline Aug & 14.51 & -0.01320 & -0.02407 & $2.25 E-5$ & $4.76 \mathrm{E}-5$ & $1.73 E-5$ & -0.0084 & 0.55 & 0.50 & 10.7 \\
\hline Sep & 14.57 & -0.01744 & -0.03174 & $2.83 E-5$ & $6.07 E-5$ & $2.03 E-5$ & -0.0089 & 0.56 & 0.56 & 9.3 \\
\hline Oct & 12.97 & -0.02080 & -0.03255 & $3.37 E-5$ & $6.16 \mathrm{E}-5$ & $2.27 E-5$ & -0.0082 & 0.61 & 0.51 & 7.3 \\
\hline Nov & 11.80 & -0.02902 & -0.04697 & $4.59 E-5$ & $8.73 E-5$ & $3.57 E-5$ & -0.0083 & 0.68 & 0.55 & 3.9 \\
\hline Dec & 9.43 & -0.02318 & -0.04051 & $3.87 E-5$ & $7.53 E-5$ & $2.84 E-5$ & -0.0076 & 0.69 & 0.52 & 2.9 \\
\hline Mean & & & & & & & -0.0084 & 0.63 & 0.50 & 5.9 \\
\hline
\end{tabular}



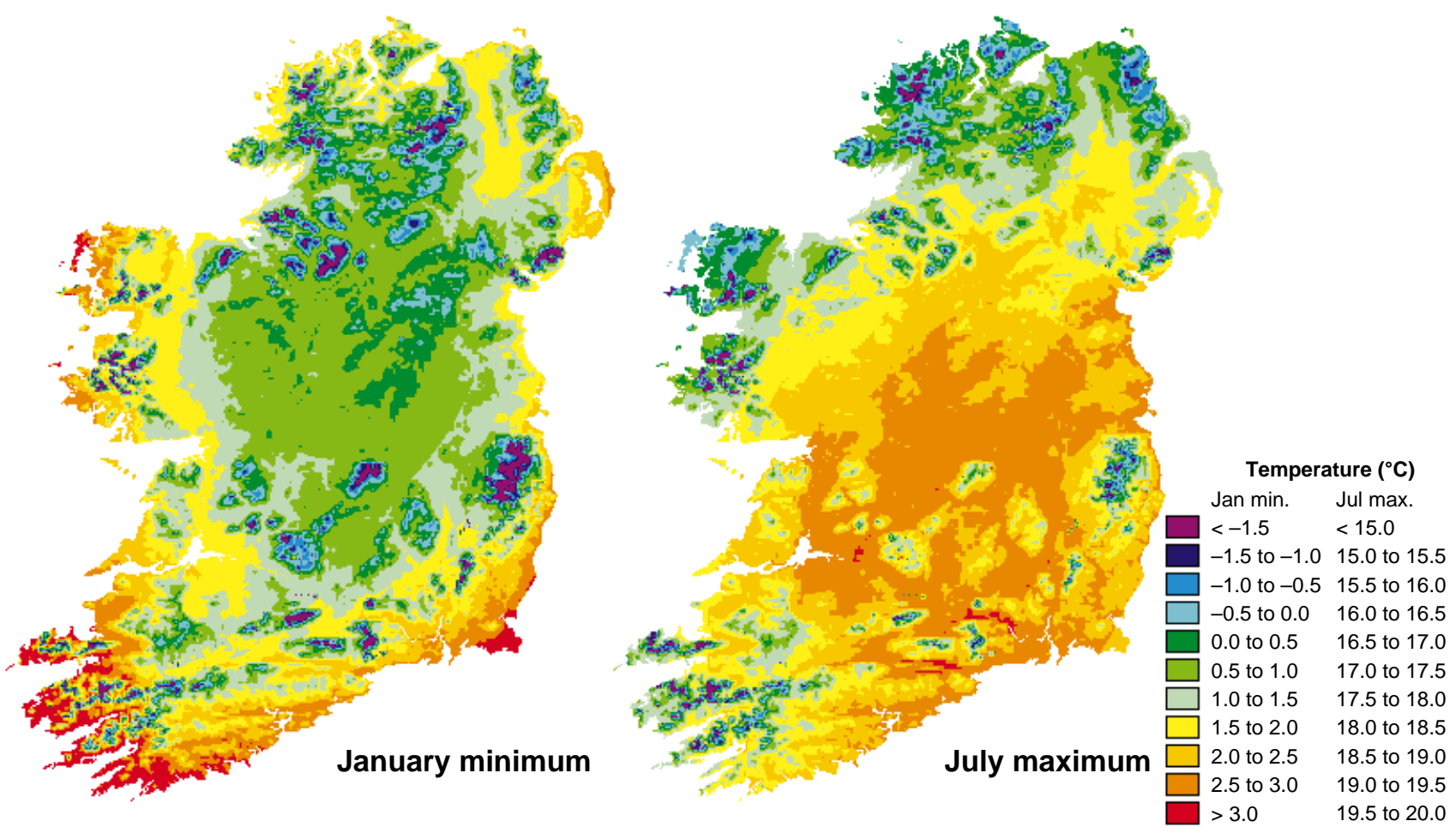

Fig. 9. Average J anuary minimum daily temperature and J uly maximum daily temperature $\left({ }^{\circ} \mathrm{C}\right)$ predicted from the coefficients listed in Table 6 and the DEM

pattern suggested oceanic moderation of minimum temperature around a generalized perimeter of Ireland. Maximum temperatures followed this pattern during the winter, but the pattern reversed during the warmer months (March to October). The coefficients for the warmer months described an inverted $U$, indicating that maximum temperatures were warmer at Ireland's center than at the edges (Fig. 9). In the summer months, the north-south inflection point was in the south of Ireland, reflecting a trend of increasing maximum temperature from north to south.
Sunshine hours: Elevation was not a significant predictor of sunshine hours for any month, and was not included in the regression equations. T. Keane (1986) reports that cloudiness increases with elevation by approximately $5 \%$ for each $100 \mathrm{~m}$ in elevation, but the limited elevation range within the sunshine hour data set (Table 1) may not have been sufficient to demonstrate this pattern.

On average, polynomial regression described $69 \%$ of the spatial variability of monthly averaged daily sunshine hours (Table 7 ) and adjusted $R^{2}$ values

Table 7. Regression statistics for predicting monthly averaged sunshine hours per day from row (km), column ( $\mathrm{km}$ ) and elevation (m). $p<0.05$ for all coefficients when potentially collinear combinations are tested together. $n=61$. Abbreviations as in Table 5; sun. hr. =hours of bright sunshine per day

\begin{tabular}{|c|c|c|c|c|c|c|c|c|c|c|}
\hline & \multicolumn{6}{|c|}{ - Coefficients } & \multirow{2}{*}{ Adj. $R^{2}$} & \multicolumn{2}{|c|}{ SE } & \multirow{2}{*}{$\begin{array}{c}\text { Data } \\
\text { mean } \\
\text { (sun. hr.) }\end{array}$} \\
\hline & $\begin{array}{c}\text { Const. } \\
\mathrm{b}_{0}\end{array}$ & $\begin{array}{c}\text { Row } \\
b_{1}\end{array}$ & $\begin{array}{c}\text { Col. } \\
\mathrm{b}_{2}\end{array}$ & $\begin{array}{c}\text { Row }^{2} \\
b_{3}\end{array}$ & $\begin{array}{c}\text { Col. }^{2} \\
\mathrm{~b}_{4}\end{array}$ & $\begin{array}{c}\text { Row } \times \text { Col } . \\
b_{5}\end{array}$ & & (sun. hr.) & (\% mean) & \\
\hline J an & 1.25 & 0.00254 & -0.00235 & $-2.06 E-6$ & $7.83 E-6$ & $-4.87 E-7$ & 0.67 & 0.11 & $7 \%$ & 1.62 \\
\hline Feb & 2.79 & 0.00051 & -0.00591 & $-3.14 E-8$ & $1.34 \mathrm{E}-5$ & $1.96 \mathrm{E}-6$ & 0.57 & 0.10 & $4 \%$ & 2.45 \\
\hline Mar & 4.34 & -0.00310 & -0.00802 & $4.79 E-6$ & $1.58 \mathrm{E}-5$ & $6.50 E-6$ & 0.52 & 0.11 & $3 \%$ & 3.38 \\
\hline Apr & 7.23 & -0.00942 & -0.01500 & $1.46 E-5$ & $3.06 E-5$ & $1.38 E-5$ & 0.65 & 0.17 & $3 \%$ & 5.08 \\
\hline May & 8.65 & -0.01041 & -0.01945 & $1.54 E-5$ & $3.81 E-5$ & $1.72 \mathrm{E}-5$ & 0.53 & 0.24 & $4 \%$ & 5.92 \\
\hline J un & 8.19 & -0.01136 & -0.02030 & $1.88 E-5$ & $4.59 E-5$ & $1.68 \mathrm{E}-5$ & 0.70 & 0.26 & $5 \%$ & 5.71 \\
\hline Jul & 6.02 & -0.00778 & -0.01664 & $1.73 E-5$ & $3.95 E-5$ & $1.31 E-5$ & 0.81 & 0.25 & $5 \%$ & 4.59 \\
\hline Aug & 6.80 & -0.00890 & -0.01807 & $1.41 E-5$ & $3.63 E-5$ & $1.95 E-5$ & 0.73 & 0.22 & $5 \%$ & 4.69 \\
\hline Sep & 5.06 & -0.00486 & -0.01397 & $8.20 E-6$ & $2.99 E-5$ & $1.36 \mathrm{E}-5$ & 0.74 & 0.18 & $5 \%$ & 3.76 \\
\hline Oct & 3.01 & 0.00079 & -0.00857 & $-3.15 E-7$ & $2.12 \mathrm{E}-5$ & $5.77 \mathrm{E}-6$ & 0.77 & 0.14 & $5 \%$ & 2.78 \\
\hline Nov & 1.32 & 0.00321 & -0.00222 & $-2.61 E-6$ & $9.76 \mathrm{E}-6$ & $-4.88 E-7$ & 0.82 & 0.10 & $5 \%$ & 1.96 \\
\hline Dec & 0.69 & 0.00342 & -0.00210 & $-2.56 E-6$ & $8.63 E-6$ & $-7.09 E-7$ & 0.82 & 0.11 & $8 \%$ & 1.33 \\
\hline Mean & & & & & & & 0.69 & 0.17 & $5 \%$ & 3.60 \\
\hline
\end{tabular}


Table 8. Correlation coefficients between observed climate values and values predicted by 2 interpolation procedures: polynomial regression, and a modified inverse-distance-squared weighting procedure. $n=100$ for precipitation and $\mathrm{n}=30$ for temperature and sunshine hours

\begin{tabular}{|c|c|c|c|c|c|c|c|c|}
\hline & $\begin{array}{l}\text { Pre } \\
\text { Jun }\end{array}$ & $\begin{array}{l}\text { cip. } \\
\text { Dec }\end{array}$ & $\begin{array}{l}\text { Max. } \\
\text { Jan }\end{array}$ & $\begin{array}{l}\text { temp. } \\
\text { J ul }\end{array}$ & $\begin{array}{l}\text { Min. } \\
\text { J an }\end{array}$ & $\begin{array}{l}\text { temp. } \\
\text { J ul }\end{array}$ & $\begin{array}{l}\text { Sunst } \\
\text { May }\end{array}$ & $\begin{array}{l}\text { h. hrs } \\
\text { Dec }\end{array}$ \\
\hline $\begin{array}{l}\text { Polynomial } \\
\text { regression }\end{array}$ & 0.92 & 0.94 & 0.95 & 0.90 & 0.77 & 0.69 & 0.45 & 0.85 \\
\hline $\begin{array}{l}\text { Inverse- } \\
\text { distance-squared }\end{array}$ & 0.91 & 0.92 & 0.97 & 0.89 & 0.72 & 0.70 & 0.29 & 0.79 \\
\hline
\end{tabular}

explicit treatment of the effects of elevation on climate than other maps of Irish climate (Hamilton et al. 1988). However, the regression models presume a consistent, linear effect of elevation on precipitation and temperature. If precipitation does not continue to increase at high elevations, the model could substantially overestimate montane precipitation. Similarly, the DEM's positive bias in mountainous regions could lead to overestimates in precipitation and underesti-

ranged from 0.52 to 0.82 (Fig. 7). The average standard error was $0.17 \mathrm{~h}$ (10 $\mathrm{min})$.

The coefficients on column and column ${ }^{2}$ described $\mathrm{U}$-shaped distributions of sunshine hours along the east-west axis. The coefficients for row and row ${ }^{2}$ described patterns that differed according to season. During the warm months, sunshine hours followed a clear U-shaped pattern along the north-south axis. During the late fall and winter, the $U$ pattern was inverted, and sunshine hours increased continually from north to south without reaching a theoretical inflection point until far south of Ireland.

Accuracy assessment. The small number of mid- to high-elevation climate stations precludes a quantitative analysis of model accuracy at the elevations where forestry is most common. The climate models contained specific elevation factors that allowed more mates in temperature. A sensitivity analysis of the forest productivity model has indicated that climate prediction errors of the magnitude indicated in Tables 5, $6 \& 7$ will affect predictions of tree growth by less than 5\% (Goodale et al. 1998).

There were no consistent differences between the accuracy of the polynomial regression and the modified inverse-distance-squared interpolations, as indicated by correlation coefficients between predicted and observed values (Table 8), plots of predicted versus observed values (Fig. 10), and statistical comparisons of predictions and errors (Table 9).

Precipitation: Predictions of J une and December rainfall correlated strongly with observed values for both interpolation techniques (Fig. 10, Table 8). The polynomial regression procedure significantly overestimated December precipitation by an average of

Table 9. Summary statistics for predictions of J une and December precipitation ( $\mathrm{mm}$ ), J anuary and J uly maximum and minimum daily temperature $\left({ }^{\circ} \mathrm{C}\right)$, and $\mathrm{M}$ ay and December sunshine hours from the polynomial regression and inverse-distance-squared methods of interpolation. Means were compared with 1-way ANOVAs. Significant differences at $p<0.05$ are indicated by an asterisk

\begin{tabular}{|c|c|c|c|c|c|c|}
\hline & $\begin{array}{l}\text { Mean value } \\
\quad( \pm 1 \mathrm{SD})\end{array}$ & Bias & MAE & $\begin{array}{l}\text { Mean value } \\
\quad( \pm 1 \mathrm{SD})\end{array}$ & Bias & MAE \\
\hline Precipitation (mm, $\mathrm{n}=100$ ) & \multicolumn{3}{|c|}{ J une } & \multicolumn{3}{|c|}{ - December - } \\
\hline Observed values & $74 \pm 22$ & & & $139 \pm 49$ & & \\
\hline Polynomial regression & $76 \pm 20$ & 1.8 & 6.8 & $144 \pm 49$ & $4.4^{*}$ & 13.5 \\
\hline Inverse-distance-squared & $77 \pm 23$ & 2.3 & 5.2 & $129 \pm 42$ & $-9.8^{*}$ & 14.7 \\
\hline \multirow{2}{*}{\multicolumn{4}{|c|}{ Max. temp. $\left({ }^{\circ} \mathrm{C}, \mathrm{n}=30\right)$}} & \multirow{2}{*}{\multicolumn{3}{|c|}{$18.6 \pm 1.1$}} \\
\hline Observed values & $7.4 \pm 0.8$ & & & & & \\
\hline Polynomial regression & $7.4 \pm 0.8$ & -0.02 & 0.16 & $18.7 \pm 0.8$ & 0.10 & 0.43 \\
\hline Inverse-distance-squared & $7.4 \pm 0.8$ & -0.04 & 0.16 & $18.7 \pm 0.7$ & 0.12 & 0.42 \\
\hline \multicolumn{4}{|l|}{ Min. temp. $\left({ }^{\circ} \mathrm{C}, \mathrm{n}=30\right)$} & \multicolumn{3}{|c|}{-July } \\
\hline Observed values & $1.6 \pm 0.95$ & & & $10.9 \pm 0.65$ & & \\
\hline Polynomial regression & $1.7 \pm 0.91$ & 0.07 & 0.53 & $10.9 \pm 0.66$ & 0.08 & 0.44 \\
\hline Inverse-distance-squared & $1.6 \pm 0.92$ & -0.01 & 0.55 & $10.9 \pm 0.77$ & 0.05 & 0.45 \\
\hline \multicolumn{4}{|l|}{ Sunshine hours $(h, n=30)$} & \multicolumn{3}{|c|}{ December } \\
\hline Observed values & $5.91 \pm 0.31$ & & & $1.35 \pm 0.23$ & & \\
\hline Polynomial regression & $5.90 \pm 0.21$ & -0.01 & 0.24 & $1.34 \pm 0.22$ & -0.01 & 0.10 \\
\hline Inverse-distance-squared & $5.94 \pm 0.20$ & 0.03 & 0.26 & $1.35 \pm 0.20$ & 0.01 & 0.11 \\
\hline
\end{tabular}



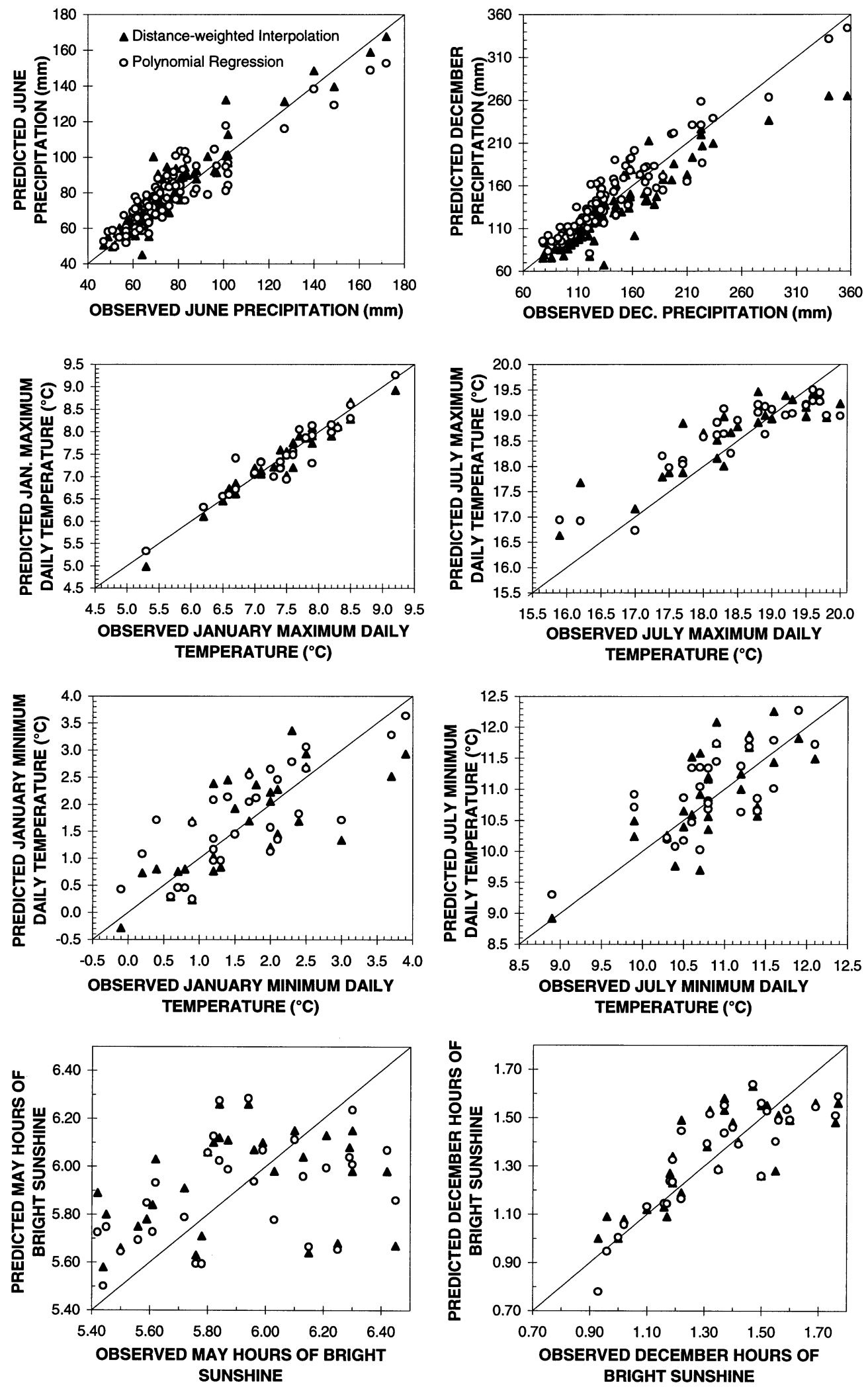

Fig. 10. Polynomial regression (open circles) and distance-weighted interpolation (closed triangles) estimates of J une and December precipitation ( $n=100)$, J anuary and J uly maximum and minimum temperature $(n=30)$, and May and December sunshine hours compared to observed values $(n=30)$. The $1: 1$ lines describe perfect fits 
$4.4 \mathrm{~mm}$, while the inverse-distance-squared method underestimated observed values by an average of $9.8 \mathrm{~mm}$ (Table 9). However, M AEs did not differ significantly between the 2 methods. Both MAEs represented approximately $10 \%$ of observed December precipitation.

Temperature: Both interpolation procedures estimated J anuary maximum temperature quite reliably (Fig. 10). Correlation coefficients between predicted and observed values were $\geq 0.95$ for both methods (Table 8), and both sets of predictions were, on average, within $0.16^{\circ} \mathrm{C}$ of observed J anuary maximum temperature. Predictions of J uly maximum temperature were not as accurate those for J anuary, but absolute differences between predicted and observed July maximum temperatures averaged only $0.4^{\circ} \mathrm{C}$ for both interpolation methods (Table 9). Both interpolation methods overestimated temperatures at the coolest sites, and underestimated temperatures at the warmest sites (Fig. 10).

Minimum temperature estimates for J anuary and J uly were not as accurate as those for maximum temperature (Tables $8 \& 9$, Fig. 10), but MAEs for both months were quite low, at approximately $0.5^{\circ} \mathrm{C}$. The simple climate models may have predicted minimum temperatures less reliably because of local-scale temperature inversions or nighttime cold-air drainage. Neither J anuary nor J uly minimum temperature estimates were consistently biased (Table 9).

Sunshine hours: While both interpolation methods produced unbiased estimates of $M$ ay sunshine hours (Table 9), Fig. 10 illustrated that neither interpolation method predicted the appropriate duration of sunshine at the appropriate location. Correlation coefficients between predicted and observed values were low for both procedures (Table 8), indicating that grid position was not a good predictor of sunniness in M ay. The variability of May sunshine hours among measurement sites was quite small (Fig. 5). MAEs for both interpolation procedures averaged approximately $15 \mathrm{~min}$ (Table 9). December predictions were more reliable than those for May (Tables $8 \& 9$, Fig. 10). Both interpolation procedures estimated December sunshine hours with MAEs of approximately 6 min.

\section{CONCLUSIONS}

For most of Ireland, the DEM was accurate to within $\pm 30 \mathrm{~m}$. Errors in the DEM translated into errors in precipitation and temperature estimates: a 30 m error in elevation changed monthly precipitation estimates by an average of $5 \mathrm{~mm}$, and monthly averaged maximum and minimum daily temperature estimates by a mean of $0.24^{\circ} \mathrm{C}$. The errors in climate due to a $30 \mathrm{~m}$ over- or underestimate of elevation were of the same magnitude as the mean errors obtained from the polynomial regression interpolations.

Simple polynomial regressions explained 52 to $93 \%$ of the spatial variability in monthly precipitation, monthly averaged maximum and minimum daily temperature, and monthly averaged daily hours of bright sunshine in Ireland. The range of measurement variability within a month was quite small for the temperature and sunshine hour data sets; yet, simple equations were still able to describe much of the existing variability. Even in the cases where adjusted $R^{2}$ values were low, standard errors of prediction were small, averaging $17 \mathrm{~mm}$ for precipitation, less than $0.5^{\circ} \mathrm{C}$ for maximum and minimum temperature, and $10 \mathrm{~min}$ for sunshine hours. Errors of this magnitude should not substantially affect ecosystem model predictions of carbon and water cycling.

No consistent differences in accuracy were discerned between polynomial regression and a commonly used method, an inverse-distance-squared interpolation. However, the climate models from the polynomial regression procedure demanded far less generation time and disk storage space compared to the distance-weighted procedure. Both of these factors greatly facilitate regional modeling of ecosystem processes within the framework of a raster geographic information system.

Acknowledgements. We thank the Forest Ecosystem Research Group at University College, Dublin, and Caitlin, Colleen, and Patrick Aber for their contributions to this project. Elevation data were used with permission from the Ordnance Survey (Permit \#6131). Dr C. Anthony Federer, Dr Russell Congalton, and 2 anonymous reviewers provided helpful comments. This paper was derived from a thesis submitted to the Graduate School at the University of New Hampshire as part of the requirements for completion of a Master of Science degree. Financial support was provided by EPA Cooperative Agreement \#82048201.

\section{LITERATURE CITED}

A ber J D, Driscoll C, Federer CA, Lathrop R, Lovett G, M ellilo J M, Steudler P, Vogelmann J (1993) A strategy for the regional analysis of the effects of physical and chemical climate change on biogeochemical cycles in northeastern (U.S.) forests. Ecol Model 67:37-47

A ber J D, Federer CA (1992) A generalized, lumped-parameter model of photosynthesis, evapotranspiration and net primary production in temperate and boreal forest ecosystems. Oecologia 92:463-474

A ber J D, Ollinger SV, Federer CA, Kicklighter DW, Melillo J M , Lathrop RGJ , Ellis J M (1995) Predicting the effects of climate change on water yield and forest production in the northeastern United States. Clim Res 5:207-222

Angstrom A (1924) Solar and terrestrial radiation. Q J R Meteorol Soc 50:121

Bacchi B, Kottegoda NT (1995) Identification and calibration of 
spatial correlation patterns of rainfall.J Hydrol 165:311-348

Belfast M eteorological Office (1988) The climate of Northern Ireland. Climatol Mem 143

Bonan GB (1989) A computer model of the solar radiation, soil moisture, and soil thermal regimes in boreal forests. Ecol Model 45:275-306

Bristow KL, Campbell GS (1984) On the relationship between incoming solar radiation and daily maximum and minimum temperature. Agric For M eteorol 31:159-166

Brock TD (1981) Calculating solar radiation for ecological studies. Ecol Model 14:1-19

Burke IC, Schimel DS, Yonker CM, Parton WJ, J oyce LA, Lauenroth WK (1990) Regional modeling of grassland biogeochemistry using GIS. Landscape Ecol 4:45-54

Burrough PA (1986) Principles of geographical information systems for land resources assessment. Oxford University Press, Oxford

Creutin J D, Obled C (1982) Objective analysis and mapping techniques for rainfall fields: an objective comparison. Water Resour Res 18:413-431

Daly C, N eilson RP, Phillips DL (1994) A statistical-topographical model for mapping climatological precipitation over mountainous terrain. J Appl Meteorol 33:140-158

Dingman SL (1981) Elevation: a major influence on the hydrology of New Hampshire and Vermont, USA. Hydrol Sci Bull 26:399-413

Dingman SL, Seely-Reynolds DM, Reynolds RC III (1988) Application of kriging to estimating mean annual precipitation in a region of orographic influence. Water Resour Bull 24:329-339

Dubayah R, Dozier J, Davis FW (1990) Topographic distribution of clear-sky radiation over the Konza Prairie, Kansas. Water Resour Res 26:679-690

Eklundh L, M årtensson U (1995) Rapid generation of digital elevation models from topographic maps. Int J GIS 9: 329-340

Fitzgerald D (1984) Monthly and annual averages of rainfall for Ireland 1951-1980. Climatological Note No. 7, Irish Meteorological Service, Dublin

Gardiner MJ , Radford T (1980) Ireland general soil map, 2nd edn. National Soil Survey, An Foras Taluntais, Dublin

Glassy J M, Running SW (1994) Validating diurnal climatology logic of the MT-CLIM model across a climatic gradient in Oregon. Ecol Appl 4:248-257

Goodale CL, Aber J D, Farrell EP (1998) Predicting the relative sensitivity of forest production in Ireland to site quality and climate change. Clim Res 10:51-67

Hamilton JEM, Lennon P, O'Donnell B (1988) Objective analysis of monthly climatological fields of temperature, sunshine, rainfall percentage and rainfall amount. J Climatol 8:109-124

Hamilton LC (1992) Regression with graphics: a second course in applied statistics. Brooks/Cole Publishing Company, Belmont, CA

Henry AJ (1919) Increase of precipitation with altitude. Mon Weather Rev 47:33-41

Hevesi J A, Istok J D, Flint AL (1992) Precipitation estimation

Editorial responsibility: Brent Yarnal,

University Park, Pennsylvania, USA in mountainous terrain using multivariate geostatistics. Part I: Structural analysis. J Appl Meteorol 31:661-676

Iqbal M (1983) An introduction to solar radiation. Academic Press, Toronto

Keane D (1985) Air temperature in Ireland 1951-1980: monthly, seasonal and annual mean and extreme values. Climatological Note No. 8. M eteorological Service, Dublin

Keane D (1986) Monthly, seasonal and annual mean and extreme values of duration of bright sunshine in Ireland 1951-1980. Climatological Note No. 9, Meteorological Service, Dublin

Keane T (1986) Climate, weather and Irish agriculture. J oint Working Group on Applied Agricultural Meteorology (AGMET), c/o M eteorological Service, Dublin

Landsberg HE (1981) The urban climate. International Geophysics Series. Academic Press, New York

Lutgens FK, Tarbuck EJ (1995) The atmosphere, 6th edn. Prentice-Hall, Englewood Cliffs, NJ

McEntee MA (1980) A revision of the equation relating sunshine hours to radiation income for Ireland. Ir J Agric Res 19:119-125

Milankovitch M (1930) Mathematische Klimalehre und astronomische Theorie der Klimaschwankungen. Handbuch der Klimatologie. Gebrüder Borntraeger, Berlin

Ollinger SV, Aber J D, Federer CA, Lovett GM, Ellis J (1995) Modeling physical and chemical climatic variables across the Northeastern U.S. for a geographic information system. U.S. Forest Service General Technical Report NE191, Radnor, PA

Ollinger SV, A ber J D, Lovett GM, Millham SE, Lathrop RG Ellis J M (1993) A spatial model of atmospheric deposition for the northeastern U.S. Ecol Appl 3:459-472

Raich J W, Rastetter EB, M elillo J M, Kicklighter DW, Steudler PA, Peterson BJ , Grace AL, Moore B III, Vorosmarty CJ (1991) Potential net primary productivity in South America: application of a global model. Ecol Appl 1:339-429

Rohan PK (1986) The climate of Ireland, 2nd edn. Meteorological Service, Dublin

Running SW, Coughlan JC (1988) FOREST-BGC, a general model of forest ecosystem processes for regional applications. I. Hydrologic balance, canopy gas exchange and primary production processes. Ecol M odel 42:125-154

Running SW, Nemani RR, Hungerford RD (1987) Extrapolation of synoptic meteorological data in mountainous terrain and its use for simulating forest evapotranspiration and photosynthesis. Can J For Res 17:472-483

Schermerhorn VP (1967) Relations between topography and annual precipitation in western Oregon and Washington. Water Resour Res 3:707-711

Swift LW J r (1976) Algorithm for solar radiation on mountain slopes. Water Resour Res 12:108-112

Tabios GQ III, Salas J D (1985) A comparative analysis of techniques for spatial interpolation of precipitation. Water Resour Bull 21:365-380

Varney BM (1920) Monthly variations of the precipitationaltitude relation in the central Sierra Nevada of California. Mon Weather Rev 48:648-649

Submitted: September 10, 1996; Accepted: March 24, 1997 Proofs received from author(s): M arch 30, 1998 